\title{
Preserved capacity for scene construction and shifts in perspective after hippocampal lesions
}

\author{
Nuttida Rungratsameetaweemana ${ }^{3}$ and Larry R. Squire ${ }^{1,2,3,4}$ \\ ${ }^{1}$ Veterans Affairs San Diego Healthcare System, San Diego, California 92161, USA; ${ }^{2}$ Department of Psychiatry, ${ }^{3}$ Department of \\ Neurosciences, ${ }^{4}$ Department of Psychology, University of California, San Diego, La Jolla, California 92093, USA
}

\begin{abstract}
The hippocampus has long been recognized as important for the formation of long-term memory. Recent work has suggested that the hippocampus might also be important for certain kinds of spatial operations, as in constructing scenes, shifting perspective, or perceiving the geometry of scenes and their boundaries. We explored this proposal using a task similar to one used previously that related hippocampal activity to scenes and their boundaries. In our study, participants viewed scenes from above that displayed walls and towers. After viewing each scene, participants saw a scene from ground level and judged whether it was the same as or different from the scene just presented. The number of towers and walls in each scene was manipulated so that it was possible to assess how the structure of the scene affected performance. Patients with hippocampal lesions performed similarly to controls in all task conditions and had no special difficulty as a function of the layout of a scene and its boundaries. In contrast, a patient with large medial temporal lobe (MTL) lesions was impaired. Taken together, our findings suggest that the hippocampus is not needed for scene construction, shifts in perspective, or perceiving the geometry of scenes. The impairment associated with large MTL lesions may result from damage in or near parahippocampal cortex.
\end{abstract}

The hippocampus is important for the formation of declarative memory, which provides for the representation of relationships among items and contexts (Squire 1992; Eichenbaum and Cohen 2001). It has also been suggested that the hippocampus has an additional role in spatial cognition and complex spatial discriminations (Lee et al. 2005; Maguire and Mullally 2013). This view gains support from the demonstration of specialized cells within the rodent hippocampus that carry out spatial computations (Moser et al. 2008). In humans, hippocampal activity can correlate with performance on spatial tasks (Maguire et al. 1998; Ekstrom et al. 2003; Doeller et al. 2010; Miller et al. 2013). In one study (Doeller et al. 2008), participants navigated a virtual-reality environment, memorizing positions of objects in relation to structural elements in the scene (i.e., landmarks and boundaries). Hippocampal activity was related to how well participants remembered the locations of objects in relation to boundaries.

In another study (Bird et al. 2010), participants saw scenes from above that displayed walls and towers. Each scene contained a total of five structures ( 0 to 4 walls and 1 to 5 towers). After viewing each scene, participants saw a scene at ground level (similar to Fig. 1) and judged whether it was the same as or different from the scene just presented. To encode the top-down view and then to make a judgment based on the ground-level view, participants had to remember the relative positions of all the elements in the scene. Performance followed a U shape, such that accuracy was highest when there were few walls or many walls and lowest when there was an intermediate number of walls. Yet, hippocampal activity was not related to performance accuracy but instead varied parametrically with the number of walls in the scene (lowest with few walls, highest with many walls). These findings suggested a role for the hippocampus in constructing scenes and relating scenes to environmental boundaries.

A finding of task-related hippocampal activity leaves open the question of whether the hippocampus is needed to perform the

\section{Corresponding author: Isquire@ucsd.edu}

Article is online at http://www.learnmem.org/cgi/doi/10.1101//m.047340.118. task. To address this question in the case of scene construction and shifts in perspective, we assessed performance on a spatial task similar to the one used earlier (Bird et al. 2010). We tested four patients with bilateral damage to the hippocampus and one patient with large medial temporal lobe (MTL) lesions that included hippocampus. We expected one of three possible outcomes. First, if the role of the hippocampus depends on the number of boundaries in a scene, as suggested by the fMRI findings (Bird et al. 2010), patients with hippocampal lesions should have most difficulty with scenes containing the largest number of walls. Second, the performance of patients with hippocampal lesions might follow task difficulty such that performance is best when there are few walls or many walls and worst when there is an intermediate number of walls. Third, if the task can be managed within working memory (Baddeley 2003), which is intact after hippocampal damage (Baddeley et al. 2011; Jeneson et al. 2012), then the patients should perform as well as controls.

\section{Results}

Figure 2 shows discriminability scores ( $\mathrm{d}^{\prime}$ ) across the five task conditions. Correct responses on "identical" and "different" trials were classified as hits and correct rejections, respectively, while incorrect responses on "identical" and "different" trials were classified as misses and false alarms, respectively (Green and Swets 1966; Macmillan and Creelman 2005). A two-way, mixed factorial ANOVA (hippocampal patients vs. controls, zero to five walls) revealed an effect of the number of walls $\left(F_{(4,36)}=7.0, P<0.001\right)$ but no effect of group $\left(F_{(1,9)}=0.1, P=0.7\right)$. The effect of the number of walls on discriminability scores followed a U-shape such that responses were more accurate for high and low numbers of walls and

(C) 2018 Rungratsameetaweemana and Squire This article is distributed exclusively by Cold Spring Harbor Laboratory Press for the first 12 months after the full-issue publication date (see http://learnmem.cshlp.org/site/misc/terms. xhtml). After 12 months, it is available under a Creative Commons License (Attribution-NonCommercial 4.0 International), as described at http:// creativecommons.org/licenses/by-nc/4.0/. 

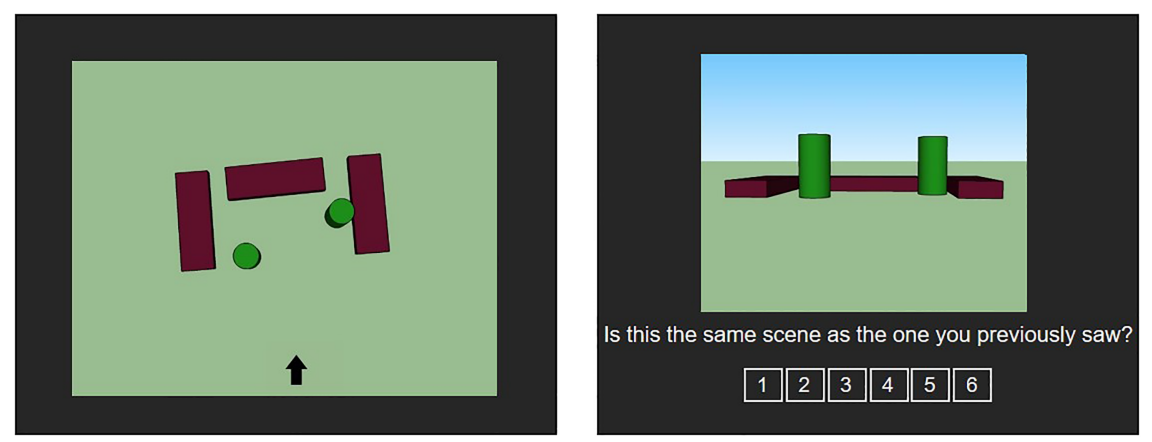

Figure 1. Participants first saw an aerial view of a scene containing five structural features (walls or towers). There were five task conditions: zero walls and five towers; one wall and four towers; two walls and three towers; three walls and two towers (as illustrated in the left panel); four walls and one tower. The arrow indicates the viewpoint from which participants would subsequently make a memory judgment about the scene. Participants then saw a ground-level view of a scene (right panel) and judged whether it was identical to the scene just presented. Participants responded using a six-point confidence rating scale $(1=$ definitely different, $6=$ definitely identical $)$. In this example, the scene in the right panel is identical to the scene in the left panel.

less accurate for intermediate numbers of walls. The hippocampal patients performed as well as controls. In contrast, the MTL patient performed more poorly than the controls when the scenes contained zero to three walls (single-sample $t$-tests, $t s_{(6)}>2.6, P \mathrm{~s}<$ 0.05). The MTL patient also performed more poorly than the hippocampal patients when the scenes contained zero or one wall (single-sample $t$-tests, $t s_{(3)}>3.6, P \mathrm{~s}<0.05$ ).

Figure 3 shows the same results in a different way (accuracy weighted by confidence ratings across five task conditions). A twoway, mixed factorial ANOVA (hippocampal patients vs. controls, zero to five walls) revealed an effect of the number of walls $\left(F_{(4,36)}=11.3, P<0.001\right)$ but no effect of group $\left(F_{(1,9)}=1.8, P=0.2\right)$. The relationship between the number of walls and weighted accuracy followed an inverted U-shape such that responses were more accurate for high and low numbers of walls and less accurate for intermediate numbers of walls. The hippocampal patients performed as well as controls. The MTL patient performed more poorly than the controls in all task conditions (single-sample $t$-tests, $\left.t s_{(6)}>2.8, P \mathrm{~s}<0.05\right)$. The MTL patient also performed more poorly than the hippocampal patients when the scenes contained zero to two walls (single-sample $t$-tests, $t s_{(6)}>4.7, P \mathrm{~s}<0.05$ ).

Figure 4 shows mean confidence rating averaged across the five task conditions. The control group, the hippocampal patients, and the MTL patient performed similarly.

\section{Discussion}

We investigated the role of the hippocampus in constructing scenes, shifting perspective and relating scenes to environmental boundaries. Participants saw a scene from a top-down view that displayed walls and towers (Fig. 1). Each scene contained a total of five structures ( 0 to 4 walls and 1 to 5 towers). Participants then saw a scene at ground level and had to judge whether the scene was identical to or different from the scene just presented. To make a correct judgment, participants had to remember the relative positions of all the walls and towers in the scene. We administered this task to memory-impaired patients with limited hippocampal lesions or large MTL lesions, expecting one of three possible results: (1) an impairment related to the number of walls in the scene, as one might predict from earlier fMRI findings (Bird et al. 2010); (2) an impairment related to task difficulty; (3) intact performance because performance can be supported by working memory.
Note that the fMRI findings in the earlier study (Bird et al. 2010) related to scene imagination, not to scene recognition. Hippocampal activity was recorded as participants imagined the just-presented scenes, not as they encoded the scenes or made recognition decisions. However, ratings of vividness were correlated with recognition accuracy. Therefore, the earlier fMRI findings do provide some basis for making predictions about the effects of hippocampal lesions on recognition performance in our task.

In our study, patients with hippocampal lesions performed similarly to controls in all five task conditions as indicated by discriminability scores $\left(\mathrm{d}^{\prime}\right)$ and by accuracy scores weighted by confidence ratings (Figs. 2, 3). Performance of both patients and controls was more accurate for scenes containing a high or low number of walls and less accurate for scenes containing an intermediate number of walls. Previous fMRI studies had suggested instead that the hippocampus is important in tasks like ours, as a function of the number of boundaries in a scene (Bird et al. 2010) or as a function of the distance between an object and a boundary (Doeller et al. 2008). Yet, in our study, the patients performed well across all conditions and had no special difficulty as a function of the characteristics of the boundaries. We suggest that the spatial task in our study could be managed within working memory, which is intact after hippocampal damage (Baddeley et al. 2011; Jeneson and Squire 2012). Other studies have also reported instances of intact performance in patients with hippocampal lesions, either because participants can rely on working memory or because performance may be supported by the adjacent parahippocampal cortex (Bohbot et al. 1998; Bohbot and Corkin 2007; Kolarik et al. 2016).

These findings suggest that the hippocampus is not needed for the spatial computations that support scene construction and shifts in perspective. The results are consistent with earlier studies of shifts in viewpoint, path integration, and map reading showing that patients with hippocampal lesions performed as well as

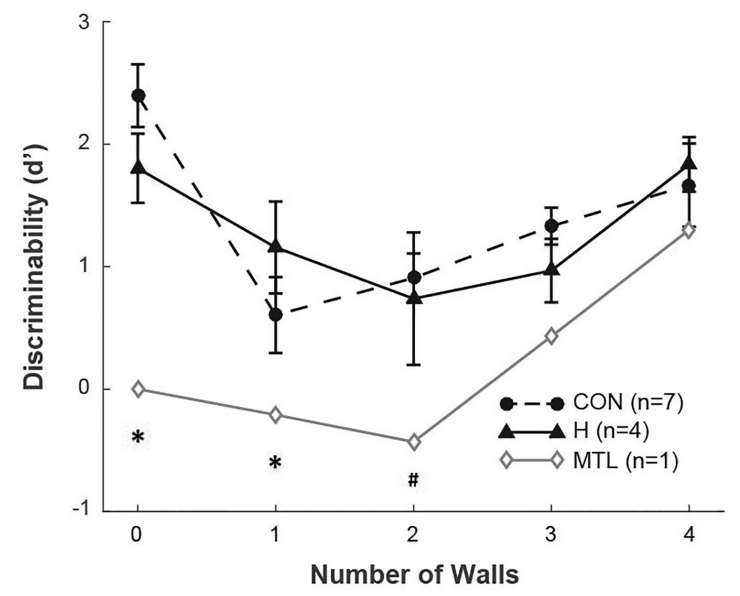

Figure 2. Performance $\left(d^{\prime}\right)$ as a function of the number of walls. (CON) controls, $(H)$ patients with hippocampal lesions, (MTL) patient with large medial temporal lobe lesions. Error bars show SEM. $\left({ }^{*}\right) P<0.05$ in comparison to $\mathrm{H}$ or CON group. (\#) $P<0.01$ in comparison to CON group. 


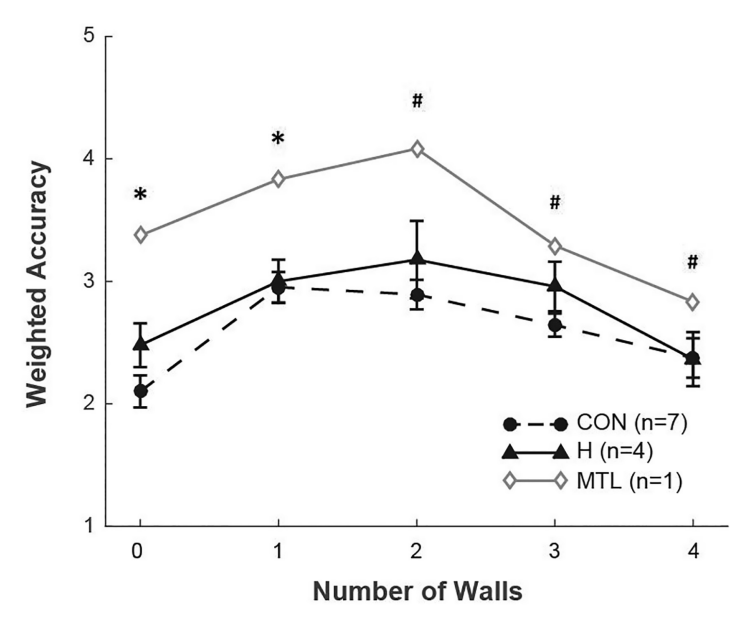

Figure 3. Accuracy weighted by confidence ratings as a function of the number of walls. Lower scores indicate better performance. For example, a score of 2 indicates a correct memory judgment with a medium confidence rating (i.e., a response of 2 on the 1-6 confidence rating scale when the test scene was different from the scene just presented or a response of 5 when the test scene was identical to the scene just presented). (CON) controls, (H) patients with hippocampal lesions, (MTL) patient with large medial temporal lobe lesions. Error bars show SEM. $\left(^{*}\right) P<0.05$ in comparison to $\mathrm{H}$ and CON groups. (\#) $P<0.05$ in comparison to $\mathrm{CON}$ group.

controls, apparently by using working memory to hold spatial information in mind as they navigated in space (Shrager et al. 2007, 2008; Kim et al. 2013; Urgolites et al. 2017). The current finding, together with these earlier results, counts against the idea that the hippocampus has an essential role in spatial cognition independent of its role in the formation of long-term memory.

Our task was based on the task used by Bird et al. (2010), but differed in two potentially important ways. First, in the earlier study, the study scene was presented from a top-down view (as in our task), but the test scene was a ground-level view containing only a subset of walls and towers from the study scene. Participants indicated whether the ground-level scene was consistent or inconsistent with the study scene. In contrast, the test scene in our study contained all the structures from the study scene (i.e., the same number of walls and towers), and participants reported whether the test scene was identical to or different from the study scene. Second, in the earlier study, participants did not know from which perspective they would be viewing the test scene. In our study, an arrow presented with the study scene indicated the perspective from which participants would view the test scene. These differences likely made the task from the earlier study more difficult than the task we used. In addition, using an arrow to indicate the perspective from which a participant would be tested may have encouraged the development of an egocentric representation of the scene. In contrast, the task from the earlier study may have depended on an allocentric representation. It is therefore possible that our patients would be impaired if they were given the earlier version of the task, because a different strategy might be needed or because the task requirements would exceed what could be managed by working memory. It is also possible that patients would be impaired if the task was made more difficult by using other conditions from Bird et al. (2010) that increased the color complexity of the scene.

Unlike the patients with hippocampal lesions, patient G.P. who has large MTL lesions, performed worse than controls across all five task conditions. His performance followed task difficulty, in that he (like controls) scored more poorly for scenes containing an intermediate number of walls and better for scenes containing a low or high number of walls. Importantly, his impairment did not become more severe with increasing number of boundaries as might have been expected from earlier fMRI findings (Bird et al. 2010). We suggest that damage in or near parahippocampal cortex contributes to G.P.'s impairment. In humans, a region termed the parahippocampal place area (PPA) was reported to respond selectively to scenes that displayed layouts of space (Epstein and Kanwisher 1998). The PPA is thought to encompass posterior parahippocampal cortex and portions of the fusiform and lingual gyri (Baldassano et al. 2013; Marchette et al. 2015). Damage to this region in humans impaired performance on tasks of spatial memory, perhaps due to a deficit in the processing of information about the geometry of surrounding space (Epstein et al. 2001; Bohbot et al. 2015).

In summary, we investigated scene construction and perspective shifts in memory-impaired patients with circumscribed hippocampal lesions or large MTL lesions. The hippocampal patients performed as well as controls, but the patient with MTL lesions was impaired. We suggest that the hippocampus is not needed to carry out the computations associated with scene construction and shifts in perspective. Further, we suggest that the impaired performance of the MTL patient may result from damage in or near parahippocampal cortex and the PPA.

\section{Materials and Methods}

\section{Participants}

Five memory-impaired patients participated, four with bilateral lesions thought to be limited to the hippocampus (CA fields, dentate gyrus, and subicular complex) and one with larger MTL lesions (Table 1). Patients D.A. and G.W. became amnesic in 2011 and 2001, respectively, following a drug overdose and associated respiratory failure. K.E. became amnesic in 2004 after an episode of ischemia associated with kidney failure and toxic shock syndrome. L.J. (the only female) became amnesic during a 6-mo period in 1988 with no known precipitating event. Her memory impairment has been stable since that time. G.P. has severe memory impairment resulting from viral encephalitis in 1987.

Estimates of MTL damage were based on quantitative analysis of magnetic resonance (MR) images from 19 age-matched, healthy males for K.E., G.W., and G.P., 11 age-matched, healthy females for patient L.J. (Gold and Squire 2005), and eight young healthy males for D.A. Patients D.A., K.E., L.J., and G.W. have an average bilateral reduction in hippocampal volume of $35 \%, 49 \%, 46 \%$, and $48 \%$,

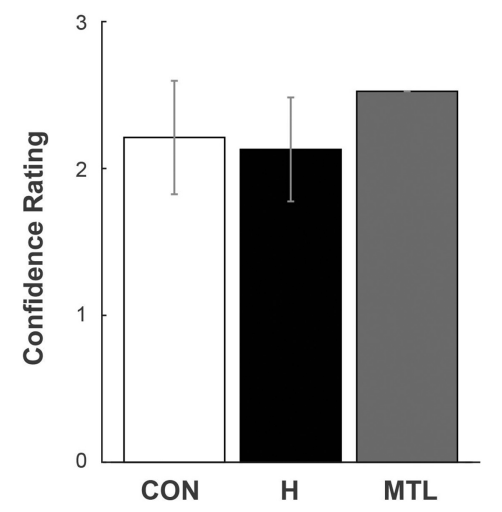

Figure 4. Mean confidence rating averaged across all five task conditions. Responses on a six-point confidence rating scale were classified as high/medium/low confidence where higher scores indicate higher confidence. For example, a score of 1 indicates low-confident responses (a response of 3 and 4 on the scene judgment task). (CON) seven controls, (H) four patients with hippocampal lesions, (MTL) one patient with large medial temporal lobe lesions. Error bars show SEM. 
Table 1. Characteristics of memory-impaired patients

\begin{tabular}{|c|c|c|c|c|c|c|c|c|}
\hline \multirow[b]{2}{*}{ Patient } & \multirow[b]{2}{*}{ Age (years) } & \multirow[b]{2}{*}{ Education (years) } & \multirow[b]{2}{*}{ WAIS-III IQ } & \multicolumn{5}{|c|}{ WMS-R } \\
\hline & & & & Attention & Verbal & Visual & General & Delay \\
\hline D.A. & 33 & 12 & 95 & 104 & 90 & 91 & 90 & 56 \\
\hline K.E. & 75 & 13.5 & 108 & 114 & 64 & 84 & 72 & 55 \\
\hline L.J. & 80 & 12 & 101 & 105 & 83 & 60 & 69 & $<50$ \\
\hline G.W. & 57 & 12 & 108 & 105 & 65 & 86 & 70 & $<50$ \\
\hline G.P. & 70 & 16 & 98 & 102 & 79 & 62 & 66 & 50 \\
\hline
\end{tabular}

WAIS-III is the Wechsler Adult Intelligence Scale-III and the WMS-R is the Wechsler Memory Scale-Revised. The WMS-R does not provide numerical scores for individuals who score $<50$. The IQ score for D.A. is from the WAIS-IV.

respectively (all values at least 2.9 SDs from the control mean). On the basis of two patients (L.M. and W.H.) with similar bilateral volume loss in the hippocampus for whom detailed postmortem neurohistological information was obtained (Rempel-Clower et al. 1996), the degree of volume loss in these four patients may reflect nearly complete loss of hippocampal neurons. The volume of the parahippocampal gyrus (temporopolar, perirhinal, entorhinal, and parahippocampal cortices) is reduced by $-5 \%, 11 \%,-17 \%$, $-5 \%, 10 \%$, and $12 \%$, respectively (all values within two SDs of the control mean for the parahippocampal gyrus as well as for each of its subsections). The minus values indicate volumes that were larger for a patient than for controls. These values are based on published guidelines for identifying the boundaries of the parahippocampal gyrus (Insausti et al. 1998; Frankó et al. 2014).

G.P. has an average bilateral reduction in hippocampal volume of $96 \%$. The volume of the parahippocampal gyrus (entorhinal, perirhinal, and parahippocampal cortex) is reduced by $94 \%$. G.P. also has a reduction in the volume of the left temporal lobe (fusiform gyrus plus inferior, medial, and superior temporal gyri) of $24 \%$. The right temporal lobe volume is reduced by only $6 \%$. Eight coronal MR images from each patient, together with detailed descriptions of the MTL lesions, can be found elsewhere (Knutson et al. 2013).

Seven healthy controls (one female) also participated (mean age $=64.9 \pm 10.3 \mathrm{yr}$; mean education $=14.0 \pm 1.5 \mathrm{yr}$ ). All procedures were approved by the Institutional Review Board at the University of California San Diego, and participants gave written informed consent prior to participation.

\section{Experimental design}

\section{Stimuli}

We used SketchUp software to create 60 unique scenes, each of which contained background, blue sky, and five structural features (zero to four brown walls and one to five dark green towers) (Fig. 1). For the study phase, the scenes were displayed from an aerial viewpoint showing the layout of the walls and towers (Fig. 1, left panel). Each scene included a black arrow at one of four possible positions (left/right/top/down). For the test phase, the scenes were displayed at ground level, such that participants faced the scene from the position indicated by the arrow (Fig. 1, right panel).

\section{Procedure}

Each trial began with the presentation of an aerial image for $3.5 \mathrm{sec}$. Participants were instructed to visualize what the layout of the scene would look like if viewed from ground level and from the position indicated by the arrow. The scene was then removed from view, and participants closed their eyes for $5 \mathrm{sec}$ to visualize a ground-level view of the scene. A tone then signaled the presentation of a ground-level image of the scene, and participants judged whether the scene was identical to or different from the justpresented scene using a six-point confidence rating scale $(1=$ definitely different, $6=$ definitely identical). No feedback was provided. The "different" scenes were scenes containing the same number of walls and towers as the study scene but arranged in a different configuration. Specifically, the elements within each scene were rearranged within a $4 \times 4$ grid, with the constraint that, in the ground-level view, no element in a scene could be occluded by another element.

One hundred twenty trials were presented (each of 60 scenes was presented twice). The test scene was identical to the study scene for half the trials. No more than three trials with identical (or different) scenes were presented consecutively. Testing was preceded by 12 practice trials with feedback in which the arrow appeared in the four possible positions equally often.

\section{Acknowledgments}

This work was supported by the Medical Research Service of the Department of Veterans Affairs (CSO00359) and NIMH (Grant 24600). We thank Nancy Kanwisher and Russell Epstein for discussion and Jennifer Frascino for assistance.

\section{References}

Baddeley A. 2003. Working memory: looking back and looking forward. Nat Rev Neurosci 4: 829-839.

Baddeley A, Jarrold C, Vargha-Khadem F. 2011. Working memory and the hippocampus. J Cogn Neurosci 23: 3855-3861.

Baldassano C, Beck DM, Fei-Fei L. 2013. Differential connectivity within the parahippocampal place area. Neuroimage 75: 228-237.

Bird CM, Capponi C, King JA, Doeller CF, Burgess N. 2010. Establishing the boundaries: the hippocampal contribution to imagining scenes. J Neurosci 30: 11688-11695.

Bohbot VD, Corkin S. 2007. Posterior parahippocampal place learning in H.M. Hippocampus 17: 863-872.

Bohbot VD, Kalina M, Stepankova K, Spackova N, Petrides M, Nadel L. 1998. Spatial memory deficits in patients with lesions to the right hippocampus and to the right parahippocampal cortex. Neuropsychologia 36: 1217-1238.

Bohbot VD, Allen JJB, Dagher A, Dumoulin SO, Evans AC, Petrides M, Kalina M, Stepankova K, Nadel L. 2015. Role of the parahippocampal cortex in memory for the configuration but not the identity of objects: converging evidence from patients with selective thermal lesions and fMRI. Front Hum Neurosci 9: 431.

Doeller CF, King JA, Burgess N. 2008. Parallel striatal and hippocampal systems for landmarks and boundaries in spatial memory. Proc Natl Acad Sci 105: 5915-5920.

Doeller CF, Barry C, Burgess N. 2010. Evidence for grid cells in a human memory network. Nature 463: 657-661.

Eichenbaum H, Cohen NJ. 2001. From conditioning to conscious recollection: memory systems of the brain. Oxford University Press, New York.

Ekstrom AD, Kahana MJ, Caplan JB, Fields TA, Isham EA, Newman EL, Fried I. 2003. Cellular networks underlying human spatial navigation. Nature 425: 184-188.

Epstein RA, Kanwisher N. 1998. A cortical representation of the local visual environment. Nature 392: 598-601.

Epstein R, DeYoe EA, Press DZ, Rosen AC, Kanwisher N. 2001. Neuropsychological evidence for a topographical learning mechanism in parahippocampal cortex. Cogn Neuropsychol 18: 481-508.

Frankó E, Insausti AM, Artacho-Pérula E, Insausti R, Chavoix C. 2014. Identification of the human medial temporal lobe regions on magnetic resonance images. Hum Brain Mapp 35: 248-256.

Gold JJ, Squire LR. 2005. Quantifying medial temporal lobe damage in memory-impaired patients. Hippocampus 15: 79-85.

Green DM, Swets JA. 1966. Signal detection theory and psychophysics. Wiley, New York. 
Insausti R, Juottonen K, Soininen H, Insausti AM, Partanen K, Vainio P, Laakso MP, Pitkänen A. 1998. MR volumetric analysis of the human entorhinal, perirhinal, and temporopolar cortices. AJNR Am J Neuroradiol 19: 659-671.

Jeneson A, Squire L. 2012. Working memory, long-term memory, and medial temporal lobe function. Learn Mem 19: 15-25.

Jeneson A, Wixted JT, Hopkins RO, Squire LR. 2012. Visual working memory capacity and the medial temporal lobe. J Neurosci 32: 3584-3589.

Kim S, Sapiurka M, Clark RE, Squire LR. 2013. Contrasting effects on path integration after hippocampal damage in humans and rats. Proc Natl Acad Sci 110: 4732-4737.

Knutson AR, Hopkins RO, Squire LR. 2013. A pencil rescues impaired performance on a visual discrimination task in patients with medial temporal lobe lesions. Learn Mem 20: 607-610.

Kolarik BS, Shahlaie K, Hassan A, Borders AA, Kaufman KC, Gurkoff G, Yonelinas AP, Ekstrom AD. 2016. Impairments in precision, rather than spatial strategy, characterize performance on the virtual Morris Water Maze: a case study. Neuropsychologia 80: 90-101.

Lee ACH, Bussey TJ, Murray EA, Saksida LM, Epstein RA, Kapur N, Hodges JR, Graham KS. 2005. Perceptual deficits in amnesia: Challenging the medial temporal lobe "mnemonic" view. Neuropsychologia 43: 1-11.

Macmillan N, Creelman D. 2005. Detection theory: a user's guide. Cambridge University Press, Cambridge.

Maguire EA, Mullally SL. 2013. The hippocampus: a manifesto for change. I Exp Psychol Gen 142: 1180-1189.

Maguire EA, Burgess N, Donnett JG, Frackowiak RS, Frith CD, O'Keefe J. 1998. Knowing where and getting there: a human navigation network. Science 280: 921-924.
Marchette SA, Vass LK, Ryan J, Epstein RA. 2015. Outside looking in: landmark generalization in the human navigational system. J Neurosci 35: $14896-14908$.

Miller JF, Neufang M, Solway A, Brandt A, Trippel M, Mader I, Hefft S, Merkow M, Polyn SM, Jacobs J, et al. 2013. Neural activity in human hippocampal formation reveals the spatial context of retrieved memories. Science 342: 1111-1114.

Moser EI, Kropff E, Moser MB. 2008. Place cells, grid cells, and the brain's spatial representation system. Annu Rev Neurosci 31: 69-89.

Rempel-Clower NL, Zola SM, Squire LR, Amaral DG. 1996. Three cases of enduring memory impairment after bilateral damage limited to the hippocampal formation. J Neurosci 16: 5233-5255.

Shrager Y, Bayley PJ, Bontempi B, Hopkins RO, Squire LR. 2007. Spatial memory and the human hippocampus. Proc Natl Acad Sci 104: 2961-2966.

Shrager Y, Kirwan CB, Squire LR. 2008. Neural basis of the cognitive map: Path integration does not require hippocampus or entorhinal cortex. Proc Natl Acad Sci 105: 12034-12038.

Squire LR. 1992. Memory and the hippocampus: a synthesis from findings with rats, monkeys, and humans. Psychol Rev 99: 195-231.

Urgolites ZJ, Hopkins RO, Squire LR. 2017. Medial temporal lobe and topographical memory. Proc Natl Acad Sci 114: 8626-8630.

Received January 19, 2018; accepted in revised form May 11, 2018. 


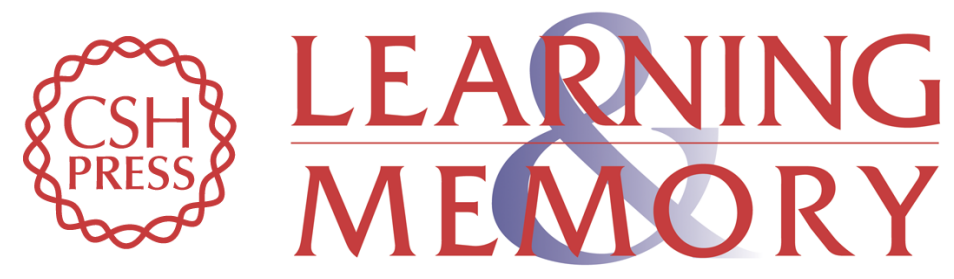

\section{Preserved capacity for scene construction and shifts in perspective after hippocampal lesions}

Nuttida Rungratsameetaweemana and Larry R. Squire

Learn. Mem. 2018, 25:

Access the most recent version at doi:10.1101/lm.047340.118

References This article cites 31 articles, 12 of which can be accessed free at:

http://learnmem.cshlp.org/content/25/8/347.full.html\#ref-list-1

Creative This article is distributed exclusively by Cold Spring Harbor Laboratory Press for the

Commons first 12 months after the full-issue publication date (see

License http://learnmem.cshlp.org/site/misc/terms.xhtml). After 12 months, it is available under a Creative Commons License (Attribution-NonCommercial 4.0 International), as described at http://creativecommons.org/licenses/by-nc/4.0/.

Email Alerting Receive free email alerts when new articles cite this article - sign up in the box at the Service top right corner of the article or click here. 